PEDAGOGISK FORSKNING I SVERIGE Vol. 26 No. 2-3 (2021) ISSN 1401-6788

\title{
Debatt
}

\section{Kunskapsbildning eller praktiknära forskning?}

Glenn Hultman

Professor emeritus, Linköpings universitet

Kontakt: glenn.hultman@liu.se

I den pågående debatten om praktiknära forskning (PFS, nr 4, 2020) är det angeläget att också rikta intresset mot den dagliga kunskapsbildningen i klassrum. Jag menar att detta borde studeras mer ingående. Kan den dagliga kunskapsbildningen uppfattas som intressant och är den till och med av teoretiskt värde? Och hur kan den förbättras?

Några debattinlägg påpekar att praktiknära forskning diskuterats under lång tid vilket också gäller samspelet mellan forskning och praktik. Ända sedan 1970-talet har forskningen om forskningsutnyttjandet diskuterats (Hultman \& Hörberg, 1994). Under många år låg fokus på forskningslogiken och tankar om överföring/implementation men det fanns tidigt de som visade ett intresse för den lokala logiken. Huberman och Weiss (odaterat manus) menade att utnyttjandet och kunskapsbildningen sker i ett samspel.

One speculation put forth here is that a more sustained, interactive dissemination ... Still, research utilization in the positivist vein, as a research-to-practice conduit, is probably beyond rescue. ... Transactions between researchers and professionals will need to become more dialectical in nature .... (Huberman \& Weiss, u.å.)

De ifrågasatte en ensidig spridningsdesign då vi arbetar med att överföra forskning till praktiken. Detta ses också hos framgångsrika system där man genomfört skolutveckling och där designen bygger på tidigare forskning (Hargreaves \& Braun, 2012). 
Lindblom (i Weiss, 1992) uppmärksammade tidigt betydelsen av vardaglig kunskap ("ordinary knowledge") som det som skapar det mesta av det vi vet och tror på.

Among the advice that he has for social scientists is not to think of research as providing answers. At best it provides ideas, offers insights, questions old assumptions, highlights new features of a situation ... Social scientists should see their work not as a substitute for lay inquiry but as an adjuncy, a help, to lay thinking. (s. 39)

Forskningen levererar inte sanningar som följs av andra, men den kan till exempel ge insikter, bidra med nya begrepp och ifrågasätta "sanningar".

Men överföringstanken har en stark dominans fortfarande vilket yttrar sig på olika sätt, till exempel idéen om evidensbaserad praktik som har kritiserats av forskare (Hultman, 2018) och den praktiska nyttan av metaanalyser (Hultman, 2015).

Min egen erfarenhet från fältet, via forskning och praktiknära skolutveckling, säger mig att det krävs mycket speciella förutsättningar för att etablera lärares (och skolledares) praktiknära forskning. Ytterligare en svårighet kan uppstå om man använder akademin som mall när det gäller metoder, redovisning (publicering) och förhållningssätt. Cochran-Smith och Lytle (2009), som har mångårig erfarenhet av lärares forskning och kunskapsbildning, använder begreppet Inquiry-as-Stance för dessa processer. Enligt dom kan det vara så att vi saknar tillräcklig kunskap om lärarens roll när det gäller kunskapsbildning med utgångspunkt $\mathrm{i}$ ett lokalt/klassrumsnära perspektiv (se även CochranSmith et al., 2016).

När det gäller lärare/rektorer som forskar så har vi mångårig erfarenhet av detta $\mathrm{i}$ termer av C-uppsatser, masteruppsatser, doktorsavhandlingar och deltagande i forskningsprojekt. Men det finns också forskning som initieras och genomförs av skolor och kommuner (Lindberg Åkerberg, 2019; Jacobsson \& Laurell, 2020; Hargreaves et al., 2018; Lindblad Petersen \& Pettersson Berggren, 2021).

Det ovan sagda för över till forskningen om kunskapsbildning och lärande i komplexa organisationer (efter en idé av Cochran-Smith \& Lytle, 1999) som redovisas nedan.

I figuren nedan illustreras olika strategier, både formella och informella, för kunskapsbildning. 
Figur 1. Strategier för kunskapsbildning

\begin{tabular}{|c|c|}
\hline $\begin{array}{l}\text { 1. Forskningsut- } \\
\text { nyttjande }\end{array}$ & $\begin{array}{l}\text { Forsknings- } \\
\text { konsumenter }\end{array}$ \\
\hline 2. Reflektion & $\begin{array}{l}\text { Reflekterande } \\
\text { praktiker }\end{array}$ \\
\hline $\begin{array}{l}\text { 3. Kollegialt } \\
\text { lärande }\end{array}$ & Aktionsforskare \\
\hline $\begin{array}{l}\text { 4. I samspråk } \\
\text { med praktiken, } \\
\text { reflektion-i- } \\
\text { handling }\end{array}$ & Vardagsexperter \\
\hline
\end{tabular}

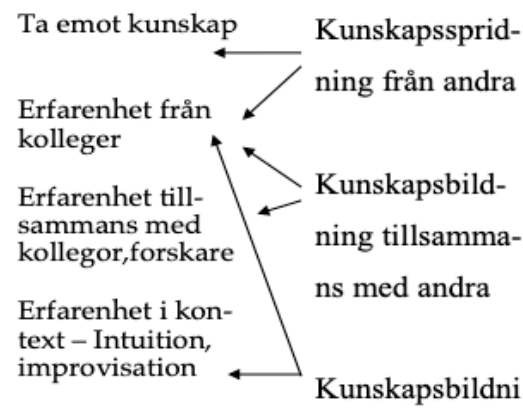

ng i vardagen

I figuren ovan illustreras de olika strategierna relativt samspelet med andra aktörer och situationer. För strategi 1 till 3 överförs kunskap eller den genereras via arrangemang som kompetensutveckling, litteratur, reflektionstillfällen, mentorskap, projekt och möten. Men för strategi 4 genereras kunskap ipraktiken, informellt och bela tiden.

Med hänvisning till figuren ovan kan man säga att vi vet för lite om strategi 3 och 4. Mitt intryck är att det finns intressant forskning inom kunskapsbildning (tyst kunskap, erfarenhetsbaserat kunnande, yrkeskunnande) men i alltför liten utsträckning. Vi behöver veta mer om skolors inre arbete och hur kunskap bildas lokalt och informellt. Och om vardagsarbetet i skolor karaktäriseras av komplexitet (Weick, 1976; Powell \& Colyvas, 2008; Stigler \& Miller, 2018) så får det konsekvenser för forskningen om miljöer som inte uppvisar en rationell logik. Erfarenheter, från praktiknära forskning (Winzell, 2018), där författaren diskuterar kunskapsbildning uppfattar att

"... lärares kunskapsbildning till stor del är situerad"... ”... lärares förståelse tycktes förändras genom erfarenheter från den elevnära verksamheten - i mötet mellan lärare, elev och innehåll”... ” ... arbetet med eleverna driver lärarna till nya insikter om skrivande som kompetensområde"... "Den erfarenhet som tycks vara mest betydelsefull för den didaktiska kunskapsbildningen är alltså lärarnas arbete tillsammans med eleverna ... det är i samspelet med eleverna som lärarna gör avgörande upptäckter om skrivundervisning” (s. 214-216).

Man kan uppfatta det så att lärare erhåller kontextuella inviter (Hultman, 2001) och att de så att säga blir situationens lärlingar och att detta är en viktig del i den beprövade erfarenheten.

Liberg (2010) menar att vi kan uppfatta läraren som antropolog som i sin lärargärning studerar både den egna och andras undervisning. Elever är också (som läraren) medvetna aktörer som gör sina val till exempel när det gäller innehåll, det vill säga de är också didaktiska aktörer. 
Eraut (2010) illustrerar hur det praktiknära och vardagliga lärandet ser ut (se även Eraut, 2002):

The most useful starting points are work alongside others ... to observe and listen ... and to participate. ... This mode of learning, which includes a lot of observation as well as discussion, is extremely important for learning tacit knowledge or the knowledge that underpins routines and intuitive decisions and is difficult to explain. When people see what is being said and done, explanations can be much shorter because the fine detail of incidents, such as the tone of voice or visual features, contributes to their understanding. ${ }^{1}$ (s. 47)

Jag har liknande empiriska erfarenheter från en studie av lärarutbildningens VFU där "närhet" framstod som en viktig princip. Den här dynamiken är viktig för vår förståelse för hur kunskap bildas men även för förståelsen av förhållandet mellan forskning och praktik.

Min mening är att det behövs ett mer omfattande arbete om vardagens kunskapsbildning, som utgår från ett ekologiskt och lokalt perspektiv, som komplement till debatten om praktiknära forskning.

\section{NOTER}

${ }^{1}$ Empiri från revisorer, ingenjörer och sköterskor

\section{REFERENSER}

Cochran-Smith, Marilyn, \& Lytle, Susan L. (1999). Relationships of knowledge and practice: teacher learning in communities. I Ashgar Iran-Nejad \& P. David Pearson, Review of Research in Education, Vol. 24 (s. 249-307). AERA.

Cochran-Smith, Marilyn, \& Lytle, Susan L. (2009). Inquiry as stance. Practitioner research for the next generation. Teachers College.

Cochran-Smith, Marylin, Villegas, Ana Maria, Whalen Abrams, Linda, ChávezMoreno, Laura C., Mills, Tammy, \& Rebecca Stern (2016). Research on teacher preparation: charting the landscape of a sprawling field. I Gitomer, D. \& Bell, C., Handbook of research on teaching (5 uppl., s.439-548). AERA.

Eraut, Michael (2002). Menus for Choosy Diners. Teachers and Teaching: theory and practice, 8(3/4), 371-379.

Eraut, Michael (2010). Knowledge, working practices, and learning. I Stephen Billet (Red.). Learning through practice. Models. Traditions, orientations and approaches (s.37-58). Springer Science+Business Media. 
Hargreaves, Andy, \& Braun, Henry (2012). Leading for all. A research report of the development, design, implementation and impact of Ontario's "Essential for some, Good for all" initiative. The code special education project. Counsil of Directors of Education, Toronto, Ontario, Canada.

Hargreaves, Andy, Shirley, Dennis, Wangia, Shaneé, Bacon, Chris, \& D’Angelo, Mark (2018). Leading from the middle: spreading learning, well-being, and identity across Ontario. Counsil of Ontario directors of education report, Toronto, Ontario, Canada.

Huberman, Michael. \& Weiss, Carol. Research Utilization at the Crossroads. Manuskript. Odaterat [1998-1999].

Hultman, Glenn \& Hörberg, Cristina (1994). Kunskapsutnyttjande. Ett informellt perspektiv på hur kunskap och forskning används i skolan. Skolverket.

Hultman, Glenn (2001). Intelligenta improvisationer. Om lärares arbete och kunskapsbildning $i$ vardagen. Studentlitteratur.

Hultman, Glenn (2015). Transformation, Interaktion eller Kunskapskonkurrens. Forskningsanvändning i praktiken. VR/UVK-rapport från SKOLFORSK.

Hultman, Glenn (2018). Konkurrensen mellan forskning och erfarenhet noteringar om forskningsanvändning i skolan. I Alvunger, Daniel \& Wahlström, Ninni, Den evidensbaserade skolan - svensk skola i skärningspunkten mellan forskning och praktik. (s.135-169). Natur \& Kultur.

Jacobsson, Andreas, \& Laurell, Michael (2020). ’Därför blir det som det blir, när vi gör som vi gör". En kvalitativ fallstudie av lärares uppfattningar om kollegialt lärande. Utbildning \& Lärande, 14(1), 7-25.

Liberg, Caroline (2010). Den didaktiska reliefen - att vara lärare. I Ulf P. Lundgren, Roger Säljö, \& Caroline Liberg, (red), Lärande, skola, bildning. Grundbok, för lärare (s.379-402). Natur \& Kultur.

Lindblad Petersen, Lena, \& Pettersson Berggren, Gunilla. (2021). Lärardriven skolutveckling - undervisning på vetenskaplig grund. Stockholm: Lärarförlaget.

Lindberg Åkerberg, Susanne (2019). Att synliggöra det osynliga. En beskrivning av ett flerairigt skolutvecklingsarbete. Forskningsrapport 10. Magelungen Utveckling AB.

Powell, Walter W., W. \& Colyvas, Jeanette A. (2008). Microfoundations of institutional theory. I Royston Greenwood, Christine Oliver, Roy Suddaby, \& Kerstin Sahlin (Red.), The SAGE Handbook of Organizational Institutionalism (s. 276298).

Stigler, James W., \& Miller, Kevin F. (2018). Expertice and expert performance in teaching. I K. Anders Ericsson (red.), The Cambridge Handbook of Expertice and Expert Performance (2 uppl., s. 431-452). Cambridge university press.

Weick, Karl E. (1976). Educational organizations as loosely coupled systems. Administrative Science Quarterly, 21, 1-19. doi:10.2307/2391875 
Winzell, Helen (2018). Lära för skrivundervisning. En studie om skrivdidaktisk kunskap i ämneslärarutbildningen och läraryrket. Linköpings universitet.

Weiss, Carol H. (1992). Research Should Supplement, Not Supplant, Lay Inquiry. Educational Researcher, 21(7), 38-40. 